\title{
Estimation of loss of genetic diversity in modern Japanese cultivars by comparison of diverse genetic resources in Asian pear (Pyrus spp.)
}

Sogo Nishio ${ }^{1 *}$, Norio Takada ${ }^{1}$, Toshihiro Saito ${ }^{1}$, Toshiya Yamamoto ${ }^{1}$ and Hiroyuki Iketani ${ }^{2}$

\begin{abstract}
Background: Pears (Pyrus spp.) are one of the most important fruit crops in temperate regions. Japanese pear breeding has been carried out for over 100 years, working to release new cultivars that have good fruit quality and other desirable traits. Local cultivar 'Nijisseiki' and its relatives, which have excellent fruit texture, have been repeatedly used as parents in the breeding program. This strategy has led to inbreeding within recent cultivars and selections. To avoid inbreeding depression, we need to clarify the degree of inbreeding among crossbred cultivars and to introgress genetic resources that are genetically different from modern cultivars and selections. The objective of the present study was to clarify the genetic relatedness between modern Japanese pear cultivars and diverse Asian pear genetic resources.
\end{abstract}

Results: We genotyped 207 diverse accessions by using 19 simple sequence repeat (SSR) markers. The heterozygosity and allelic richness of modern cultivars was obviously decreased compared with that of wild individuals, Chinese pear cultivars, and local cultivars. In analyses using Structure software, the 207 accessions were classified into four clusters $(K=4)$ : one consisting primarily of wild individuals, one of Chinese pear cultivars, one of local cultivars from outside the Kanto region, and one containing both local cultivars from the Kanto region and crossbred cultivars. The results of principal coordinate analysis (PCOA) were similar to those from the Structure analysis. Wild individuals and Chinese pears appeared to be distinct from other groups, and crossbred cultivars became closer to 'Nijisseiki' as the year of release became more recent.

Conclusions: Both Structure and PCoA results suggest that the modern Japanese pear cultivars are genetically close to local cultivars that originated in the Kanto region, and that the genotypes of the modern cultivars were markedly biased toward 'Nijisseiki'. Introgression of germplasm from Chinese pear and wild individuals that are genetically different from modern cultivars seems to be key to broadening the genetic diversity of Japanese pear. The information obtained in this study will be useful for pear breeders and other fruit breeders who have observed inbreeding depression.

Keywords: Simple sequence repeat (SSR) markers, Pyrus pyrifolia Nakai, Population structure, Principal coordinate analysis (PCOA)

\footnotetext{
* Correspondence: nishios@affrc.go.jp

${ }^{1}$ Institute of Fruit Tree and Tea Science, NARO (NIFTS), 2-1 Fujimoto, Tsukuba,

Ibaraki 305-8605, Japan

Full list of author information is available at the end of the article
} 


\section{Background}

Inbreeding is a common problem in fruit breeding programs [1-9]. It reduces vigor trait, such as tree vigor $[2,3,5,8]$, viability $[1,2,5]$ and fruit weight [4]. Selection of local cultivars from wild populations during domestication has increased productivity but narrowed genetic diversity $[10,11]$. Moreover, an organized breeding program is generally started with limited genetic resources that have been already domesticated, such as local cultivars. Introducing materials from foreign countries is not easy on account of biosecurity concerns, and introgression of superior traits from wild individuals may require several generations to reach performance comparable to that of modern cultivars. In addition, fruit trees have a long juvenile period before fruit set and seed production. Thus, most fruit breeders are likely to improve genotypes by crossing well-known cultivars $[6,12]$. As a result, the genetic diversity of modern cultivars has decreased dramatically over time.

Pears (Pyrus spp.) belong to the subtribe Pyrinae (formerly subfamily Maloideae) of the Rosaceae and are one of the most important fruit crops in temperate regions. In East Asia, major cultivated pears are traditionally classified into three species: $P$. ussuriensis Maxim., P. bretschneideri Rehder, and P. pyrifolia (Burm. f.) Nakai $[13,14]$. Many taxonomists and horticulturists have tried to classify these species using their own criteria, according to morphological characters [13, 15-17] or molecular markers [18-21]. However, these species readily produce interspecific hybrids [22], and some cultivars are admixtures of different species [18-21]. Also, the species themselves seem to be genetically continuous $[15,23-25]$. As a result, genetic classification based on these three species is obscure. Iketani et al. [25] proposed a new cultivar classification system based on the population structure of these species and historical enumeration, i.e., Pyrus Ussurian Pear Group (Pyrus ussuriensis), Pyrus Chinese White Pear Group (P. bretschneideri or P. pyrifolia), Pyrus Chinese Sand Pear Group (P. pyrifolia), and Pyrus Japanese Pear Group (P. pyrifolia). Many pear genetic diversity studies have been conducted using these various systems to classify species, groups, and cultivars. However, few studies have focused on comparison of modern cultivars with diverse genetic resources such as foreign cultivars, wild individuals, and local cultivars.

The Japanese pear breeding program began in 1909 [26] and continues to aim at developing new cultivars that ripen at various times and have high productivity and fruit quality, low production costs, high disease resistance, self-compatibility, and freedom from physiological disorders. In particular, breeding for soft fruit texture has been key to improving fruit quality [27]. Local cultivar 'Nijisseiki', which originated in the Kanto region and has been one of the leading cultivars in
Japan, has excellent fruit texture. 'Nijisseiki' and its relatives have been repeatedly used as parents in the breeding program. In addition, 'Osanijisseiki', which arose as a natural mutant from 'Nijisseiki', was released as a self-compatible cultivar and introduced into the breeding program as a means of developing additional selfcompatible cultivars [28, 29]. For these reasons, inbreeding due to repeated use of 'Nijisseiki'-biased genotypes has become a problem for Japanese pear breeding $[8,9]$. It was reported that both the pedigree-based inbreeding coefficient $(F)$ and the marker-based inbreeding coefficient increased in Japanese pear cultivars as the year of the initial cross became more recent [9]. The tree height of 1-year-old seedlings decreased by $20 \%$ for $F=0.25$ and by $40 \%$ for $F=0.5$ [8]. Also, the decrease in number of $S$-genotypes among modern cultivars is problematic with respect to mating design. These days, more and more cultivars and selections have identical $S$-genotypes, with the result that some combinations among modern cultivars are incompatible. A possible solution may lie in the diverse genetic resources (including cultivars introduced from China, local cultivars collected from all over Japan, and wild individuals) that have been preserved at Institute of Fruit Tree and Tea Science, NARO (NIFTS). We are interested in using these genetic resources to avoid inbreeding depression.

So far, the use of foreign cultivars and wild individuals in Japanese pear breeding has been limited. It is extremely difficult to obtain elite genotypes in a short period of time while at the same time broadening genetic diversity using foreign cultivars and wild individuals instead of well-adapted genotypes. To overcome this difficulty, it is necessary to genetically characterize these materials so as to determine which cultivars or individuals would be most effective for broadening genetic diversity and how much genetic diversity has been lost among modern cultivars. The objective of the present study was to clarify the degree of inbreeding among modern cultivars and to estimate the genetic relatedness between modern cultivars and diverse genetic resources. On the basis of our results, we discuss the potential to broaden genetic diversity in pear breeding programs and the trend toward loss of genetic diversity in modern pear cultivars.

\section{Methods}

\section{Plant materials}

The nine groups (207 accessions) used in this study are shown in Table 1 and Additional file 1: Table S1. Several of the materials in this study are similar to those used in Iketani et al. [25]: wild individuals of P. ussuriensis collected from the Hayasaka-Kogen high plateau in Iwate Prefecture (IWA), which were unaffected by the genetic influence of cultivated trees [25]; Chinese pear 
Table 1 List of the 207 pear accessions used in this study

\begin{tabular}{|c|c|c|c|c|c|c|c|}
\hline $\mathrm{ID}$ & Cultivar/selection & Type & $\begin{array}{l}\text { Code } \\
\text { (group number) }\end{array}$ & ID & Cultivar/selection & Type & $\begin{array}{l}\text { Code } \\
\text { (group number) }\end{array}$ \\
\hline 1 & $\mathrm{Hs}-1$ & Wild & IWA (1) & 106 & Babaucchiaginashi & Local cultivar & WJ (6) \\
\hline 2 & $\mathrm{Hs}-2$ & Wild & IWA (1) & 107 & Ichihara Wase & Local cultivar & WJ (6) \\
\hline 3 & $\mathrm{Hs}-3$ & Wild & IWA (1) & 108 & Imamuraaki & Local cultivar & WJ (6) \\
\hline 4 & $\mathrm{Hs}-4$ & Wild & IWA (1) & 109 & Imamuranatsu & Local cultivar & WJ (6) \\
\hline 5 & $\mathrm{Hs}-5$ & Wild & IWA (1) & 110 & Nansei Chabo & Local cultivar & WJ (6) \\
\hline 6 & $\mathrm{Hs}-6$ & Wild & IWA (1) & 111 & Nekogoroshi & Local cultivar & WJ (6) \\
\hline 7 & $\mathrm{Hs}-7$ & Wild & IWA (1) & 112 & Sawairiyamanashi & Local cultivar & WJ (6) \\
\hline 8 & $\mathrm{Hs}-8$ & Wild & IWA (1) & 113 & Segawa & Local cultivar & WJ (6) \\
\hline 9 & $\mathrm{Hs}-9$ & Wild & IWA (1) & 114 & Shimokatsuginashi & Local cultivar & WJ (6) \\
\hline 10 & $\mathrm{Hs}-10$ & Wild & IWA (1) & 115 & Shoumyoujinashi & Local cultivar & WJ (6) \\
\hline 11 & $\mathrm{Hs}-11$ & Wild & IWA (1) & 116 & Tosajou & Local cultivar & WJ (6) \\
\hline 12 & $\mathrm{Hs}-12$ & Wild & IWA (1) & 117 & Tosajounishiki & Local cultivar & WJ (6) \\
\hline 13 & $\mathrm{Hs}-14$ & Wild & IWA (1) & 118 & Tosanashi & Local cultivar & WJ (6) \\
\hline 14 & $\mathrm{Hs}-15$ & Wild & IWA (1) & 119 & Tsukushiinunashi & Local cultivar & WJ (6) \\
\hline 15 & $\mathrm{Hs}-16$ & Wild & IWA (1) & 120 & Waseaka Ouryuu & Local cultivar & WJ (6) \\
\hline 16 & $\mathrm{Hs}-18$ & Wild & IWA (1) & 121 & Atago & Crossbred cultivar & $\mathrm{CFH}(7)$ \\
\hline 17 & Hs-19 & Wild & IWA (1) & 122 & Ishii Wase & Crossbred cultivar & $\mathrm{CFH}(7)$ \\
\hline 18 & Baozhuli & Cultivar & BRE (2) & 123 & Higashino & Crossbred cultivar & $\mathrm{CFH}(7)$ \\
\hline 19 & Chang Xi Li & Cultivar & BRE (2) & 124 & Heiwa & Crossbred cultivar & $\mathrm{CFH}(7)$ \\
\hline 20 & Hong Li & Cultivar & BRE (2) & 125 & Gion & Crossbred cultivar & $\mathrm{CFH}(7)$ \\
\hline 21 & Hong Xiao Li & Cultivar & BRE (2) & 126 & Kikusui & Crossbred cultivar & $\mathrm{CFH}(7)$ \\
\hline 22 & Huang Li & Cultivar & BRE (2) & 127 & Sagami & Crossbred cultivar & $\mathrm{CFH}(7)$ \\
\hline 23 & $\mathrm{Mi} \mathrm{Li}$ & Cultivar & BRE (2) & 128 & Seiryuu & Crossbred cultivar & $\mathrm{CFH}(7)$ \\
\hline 24 & Mi Li Cui & Cultivar & BRE (2) & 129 & Yakumo & Crossbred cultivar & $\mathrm{CFH}(7)$ \\
\hline 25 & Tai Huang Li & Cultivar & BRE (2) & 130 & Niitaka & Crossbred cultivar & CFH (7) \\
\hline 26 & Ya Gua Li & Cultivar & BRE (2) & 131 & Asahi & Crossbred cultivar & $\mathrm{CFH}(7)$ \\
\hline 27 & Ya Li & Cultivar & BRE (2) & 132 & Yachiyo & Crossbred cultivar & $\mathrm{CFH}(7)$ \\
\hline 28 & Kuerren Xiang Li & Cultivar & BRE (2) & 133 & Hatsuaki & Crossbred cultivar & $\mathrm{CFH}(7)$ \\
\hline 29 & Lunanhuangli & Cultivar & BRE (2) & 134 & Kimizukawase & Crossbred cultivar & $\mathrm{CFH}(7)$ \\
\hline 30 & Ma Ke Zao Li & Cultivar & BRE (2) & 135 & Kougetsu & Crossbred cultivar & $\mathrm{CFH}(7)$ \\
\hline 31 & Man Yuan Xiang & Cultivar & BRE (2) & 136 & Hattatsu & Crossbred cultivar & $\mathrm{CFH}(7)$ \\
\hline 32 & Ping Li & Cultivar & BRE (2) & 137 & Shinkou & Crossbred cultivar & $\mathrm{CFH}(7)$ \\
\hline 33 & Seuri Li & Cultivar & BRE (2) & 138 & Shinseiki & Crossbred cultivar & $\mathrm{CFH}(7)$ \\
\hline 34 & Xie Hua Tian & Cultivar & BRE (2) & 139 & Seigyoku & Crossbred cultivar & CFH (7) \\
\hline 35 & Yin Bai Li & Cultivar & BRE (2) & 140 & Yanaga & Crossbred cultivar & $\mathrm{CFH}(7)$ \\
\hline 36 & Yuan Ba Li & Cultivar & BRE (2) & 141 & Shinsetsu & Crossbred cultivar & CLH (8) \\
\hline 37 & Wo Wo Li & Cultivar & BRE (2) & 142 & Hiratsuka 7 & Breeding line & CLH (8) \\
\hline 38 & Suan Li & Cultivar & BRE (2) & 143 & Hiratsuka 1 & Breeding line & CLH (8) \\
\hline 39 & Tang Li & Cultivar & BRE (2) & 144 & Hiratsuka 11 & Breeding line & CLH (8) \\
\hline 40 & Dang Shan Fu Su Li & Cultivar & BRE (2) & 145 & Kumoi & Crossbred cultivar & CLH (8) \\
\hline 41 & Ba Li Xiang & Cultivar & USS (3) & 146 & Suisei & Crossbred cultivar & CLH (8) \\
\hline 42 & Bei Jin Bai Li & Cultivar & USS (3) & 147 & Kousui & Crossbred cultivar & CLH (8) \\
\hline
\end{tabular}


Table 1 List of the 207 pear accessions used in this study (Continued)

\begin{tabular}{|c|c|c|c|c|c|c|c|}
\hline 43 & Cang Xi Li & Cultivar & USS (3) & 148 & Hiratsuka 10 & Breeding line & CLH (8) \\
\hline 44 & Dang Shan Jin Gai Su & Cultivar & USS (3) & 149 & Hiratsuka 17 & Breeding line & CLH (8) \\
\hline 45 & Dang Shan Mian Li & Cultivar & USS (3) & 150 & Hiratsuka 24 & Breeding line & CLH (8) \\
\hline 46 & Dang Shan Zi Su Li & Cultivar & USS (3) & 151 & Shinsui & Crossbred cultivar & $\mathrm{CLH}(8)$ \\
\hline 47 & Huang Shan Li & Cultivar & USS (3) & 152 & Hayatama & Crossbred cultivar & $\mathrm{CLH}(8)$ \\
\hline 48 & Hui Zhou Xue Li & Cultivar & USS (3) & 153 & Tama & Crossbred cultivar & CLH (8) \\
\hline 49 & Jian Ba Li & Cultivar & USS (3) & 154 & Housui & Crossbred cultivar & $\mathrm{CLH}(8)$ \\
\hline 50 & Lai Yang Ci Li & Cultivar & USS (3) & 155 & Hiratsuka 25 & Breeding line & $\mathrm{CLH}(8)$ \\
\hline 51 & Manshuu Yaseinashi & Cultivar & USS (3) & 156 & Hiratsuka 29 & Breeding line & CLH (8) \\
\hline 52 & Niao Li & Cultivar & USS (3) & 157 & Hiratsuka 27 & Breeding line & CLH (8) \\
\hline 53 & Ping Guo Li & Cultivar & USS (3) & 158 & Hakkou & Crossbred cultivar & CLH (8) \\
\hline 54 & Su Hyang Ri & Cultivar & USS (3) & 159 & Chouju & Crossbred cultivar & CLH (8) \\
\hline 55 & Zao Su & Cultivar & USS (3) & 160 & Hokukan & Crossbred cultivar & CLH (8) \\
\hline 56 & Zhu Zui Li & Cultivar & USS (3) & 161 & Tsukuba 34 & Breeding line & CLH (8) \\
\hline 57 & Doitsu & Local cultivar & KAN (4) & 162 & Tsukuba 35 & Breeding line & $\mathrm{CLH}(8)$ \\
\hline 58 & Choujuurou & Local cultivar & KAN (4) & 163 & Tsukuba 37 & Breeding line & CLH (8) \\
\hline 59 & Nijisseiki & Local cultivar & KAN (4) & 164 & Tsukuba 39 & Breeding line & $\mathrm{CLH}(8)$ \\
\hline 60 & Yoshino & Local cultivar & KAN (4) & 165 & Shinsei & Crossbred cultivar & $\mathrm{CLH}(8)$ \\
\hline 61 & Edoya & Local cultivar & KAN (4) & 166 & Shuugyoku & Crossbred cultivar & CLH (8) \\
\hline 62 & Rokugatsu & Local cultivar & KAN (4) & 167 & Chikusui & Crossbred cultivar & CLH (8) \\
\hline 63 & Okuroku & Local cultivar & KAN (4) & 168 & Yasato & Crossbred cultivar & $\mathrm{CLH}(8)$ \\
\hline 64 & Jouhana & Local cultivar & KAN (4) & 169 & Nansui & Crossbred cultivar & CLH (8) \\
\hline 65 & Heishi & Local cultivar & KAN (4) & 170 & Tsukuba 41 & Breeding line & CLH (8) \\
\hline 66 & Wase Kouzou & Local cultivar & KAN (4) & 171 & Tsukuba 42 & Breeding line & CLH (8) \\
\hline 67 & Kouzou & Local cultivar & KAN (4) & 172 & Tsukuba 43 & Breeding line & CLH (8) \\
\hline 68 & Shikishima & Local cultivar & KAN (4) & 173 & Tsukuba 44 & Breeding line & CLH (8) \\
\hline 69 & Shinchuu & Local cultivar & KAN (4) & 174 & Wakahikari & Crossbred cultivar & CLH (8) \\
\hline 70 & Rikiya & Local cultivar & KAN (4) & 175 & Hougetsu & Crossbred cultivar & CLH (8) \\
\hline 71 & Chousen & Local cultivar & KAN (4) & 176 & Natsuhikari & Crossbred cultivar & $\mathrm{CLH}(8)$ \\
\hline 72 & Shirayuki & Local cultivar & KAN (4) & 177 & Nikkori & Crossbred cultivar & $\mathrm{CLH}(8)$ \\
\hline 73 & Kokuchou & Local cultivar & KAN (4) & 178 & Akibae & Crossbred cultivar & CLH (8) \\
\hline 74 & Taihei & Local cultivar & KAN (4) & 179 & Akemizu & Crossbred cultivar & CLH (8) \\
\hline 75 & Sekiryuu & Local cultivar & KAN (4) & 180 & Nangetsu & Crossbred cultivar & $\mathrm{CLH}(8)$ \\
\hline 76 & Taihaku & Local cultivar & KAN (4) & 181 & Hokushin & Crossbred cultivar & CLH (8) \\
\hline 77 & Sekaiichi & Local cultivar & KAN (4) & 182 & Inagi & Crossbred cultivar & CLH (8) \\
\hline 78 & Asahiryuu & Local cultivar & KAN (4) & 183 & Aikansui & Crossbred cultivar & CLH (8) \\
\hline 79 & Kinchaku & Local cultivar & KAN (4) & 184 & Kisui & Crossbred cultivar & CLH (8) \\
\hline 80 & Koyuki & Local cultivar & KAN (4) & 185 & Yoshikaori & Crossbred cultivar & $\mathrm{CLH}(8)$ \\
\hline 81 & Saitama 2-1 & Local cultivar & KAN (4) & 186 & Tsukuba 52 & Breeding line & MDC (9) \\
\hline 82 & Saitama 8 & Local cultivar & KAN (4) & 187 & Tsukuba 53 & Breeding line & $\operatorname{MDC}(9)$ \\
\hline 83 & Amanogawa & Local cultivar & NSJ (5) & 188 & Tsukuba 49 & Breeding line & MDC (9) \\
\hline 84 & Ruisannashi & Local cultivar & NSJ (5) & 189 & Tsukuba 51 & Breeding line & $\operatorname{MDC}(9)$ \\
\hline 85 & Okusankichi & Local cultivar & NSJ (5) & 190 & Akizuki & Crossbred cultivar & MDC (9) \\
\hline
\end{tabular}


Table 1 List of the 207 pear accessions used in this study (Continued)

\begin{tabular}{|c|c|c|c|c|c|c|c|}
\hline 86 & Hakuteiryuu & Local cultivar & NSJ (5) & 191 & Nashi Chukanbohon Nou 1 Gou & Crossbred cultivar & MDC (9) \\
\hline 87 & Abumi & Local cultivar & NSJ (5) & 192 & Akiakari & Crossbred cultivar & $\operatorname{MDC}(9)$ \\
\hline 88 & Yokogoshi & Local cultivar & NSJ (5) & 193 & Oushuu & Crossbred cultivar & MDC (9) \\
\hline 89 & Awayuki & Local cultivar & NSJ (5) & 194 & Shuurei & Crossbred cultivar & MDC (9) \\
\hline 90 & Hachibuse No Nashi & Local cultivar & NSJ (5) & 195 & Natsushizuku & Crossbred cultivar & MDC (9) \\
\hline 91 & Oohiromaru & Local cultivar & NSJ (5) & 196 & Shinkansen & Crossbred cultivar & MDC (9) \\
\hline 92 & Kounowatashi & Local cultivar & NSJ (5) & 197 & Kanta & Crossbred cultivar & MDC (9) \\
\hline 93 & Miyadani & Local cultivar & NSJ (5) & 198 & Rinka & Crossbred cultivar & MDC (9) \\
\hline 94 & Onba & Local cultivar & NSJ (5) & 199 & Hatsumaru & Crossbred cultivar & MDC (9) \\
\hline 95 & Shimane Yamanashi & Local cultivar & NSJ (5) & 200 & Hoshiakari & Crossbred cultivar & $\operatorname{MDC}(9)$ \\
\hline 96 & Hakataao & Local cultivar & NSJ (5) & 201 & Tsukuba 59 & Breeding line & MDC (9) \\
\hline 97 & Kunitomi & Local cultivar & NSJ (5) & 202 & Tsukuba 60 & Breeding line & MDC (9) \\
\hline 98 & Nishitonami 1 & Local cultivar & NSJ (5) & 203 & Tsukuba 61 & Breeding line & MDC (9) \\
\hline 99 & Ookoga & Local cultivar & NSJ (5) & 204 & Tsukuba 62 & Breeding line & MDC (9) \\
\hline 100 & Shihyakume & Local cultivar & NSJ (5) & 205 & Tsukuba 63 & Breeding line & MDC (9) \\
\hline 101 & Tanponashi & Local cultivar & NSJ (5) & 206 & Tsukuba 64 & Breeding line & MDC (9) \\
\hline 102 & Touhou & Local cultivar & NSJ (5) & 207 & Narumi & Crossbred cultivar & $\operatorname{MDC}(9)$ \\
\hline 103 & Tottori 4 & Local cultivar & NSJ (5) & & & & \\
\hline 104 & Waseaka & Local cultivar & NSJ (5) & & & & \\
\hline 105 & Yagoemon & Local cultivar & NSJ (5) & & & & \\
\hline
\end{tabular}

IWA Wild individuals from Iwate, BRE P. bretschneideri cultivar, USS P. ussuriensis cultivar, KAN Local cultivar from Kanto region, NSJ Local cultivar from near the sea of Japan, WJ Local cultivar from western Japan, CFH Cultivar released in the first half of the 20th century, CLH Cultivar released in the latter half of the 20th century or breeding line developed during that time, MDC Modern cultivar (released in the 21 st century) or breeding line developed during that time

cultivars generally considered to be $P$. bretschneideri (BRE) and P. ussuriensis (USS); and Japanese pear local cultivars that originated in the Kanto region of Japan (KAN), near the Sea of Japan (NSJ), and in western Japan (WJ). We also included Japanese pear crossbred cultivars and breeding lines from the first half of the 20th century (CFH), the latter half of the 20th century (CLH), and the 21st century (MDC).

\section{SSR marker analysis}

The 207 pear accessions were genotyped for 19 simple sequence repeat (SSR) markers (Additional file 2: Table S2). PCR amplification was performed in $10 \mu \mathrm{L}$ containing $5 \mu \mathrm{L}$ of $2 \times$ Green GoTaq reaction buffer $(0.4 \mathrm{mM}$ each dNTP, $3 \mathrm{mM} \mathrm{MgCl}_{2}$, and $1 \mathrm{U}$ Taq polymerase, $\mathrm{pH} 8.5$, Promega, Madison, USA), 20 pmol of each forward primer labeled with a fluorescent chemical (FAM or HEX) and unlabeled reverse primer, and $2.5 \mathrm{ng}$ of genomic DNA. Amplification was performed in 35 cycles of $94{ }^{\circ} \mathrm{C}$ for $1 \mathrm{~min}, 55^{\circ} \mathrm{C}$ for $1 \mathrm{~min}$, and $72{ }^{\circ} \mathrm{C}$ for $2 \mathrm{~min}$. PCR products were separated and detected with a 3130 xl genetic analyzer (Life Technologies Co., Carlsbad, CA, USA). The size of each amplified band was determined by comparison with an internal DNA standard (400HD-ROX, Life Technologies) in GeneScan software (Life Technologies).

\section{Data analyses}

The observed heterozygosity $\left(H_{\mathrm{O}}\right)$ and expected heterozygosity $\left(H_{\mathrm{E}}\right)$ were calculated in GenAlEx v. 6.5 software [30], and allelic richness (AR, $n=15)$ was calculated in FSTAT v. 2.9.3 software [31]. Bayesian statistical inference on the population structure was performed in Structure v. 2.3.3 software [32] with the admixture model for ancestry and both independent and correlated models for allele frequency, without any prior information about the origin of each individual. After a burn-in period of 100,000 iterations, the analysis was run 10 times for each value of $K$ (number of inferred ancestral populations) from 2 to 10 for $1,000,000$ iterations. We used Evanno et al.'s [33] criterion of $\left|\mathrm{L}^{\prime \prime}(K)\right|=\left|\mathrm{L}^{\prime}(K+1)-\mathrm{L}^{\prime}(K)\right|=\mid \ln \mathrm{P}(\mathrm{X} \mid K+1)-2 \ln$ $\mathrm{P}(\mathrm{X} \mid K+1)+\ln \mathrm{P}(\mathrm{X} \mid K+1) \mid$ and $\Delta K=$ mean $\left(\left|\mathrm{L}^{\prime \prime}(K)\right|\right) /$ $\mathrm{s}[\mathrm{L}(K)]$ and values of plateaued $\ln \mathrm{P}(\mathrm{X} \mid K)$ to estimate the optimal value of $K$. Simulation studies have shown that once the real value of $K$ has been reached, $\ln \mathrm{P}(\mathrm{X} \mid \mathrm{K})$ will typically plateau or continue to increase slightly [33]. Principal coordinate analysis ( $\mathrm{PCoA}$ ) was calculated in GenAlEx 6.5 from the pairwise genetic distances obtained with the covariance-standardized method. Simple allelesharing distances among the 207 accessions were calculated as described [34]. All data were calculated from the genotypes of the 207 accessions based on the 19 SSR markers. 


\section{Results}

Basic genetic characteristics of pear accession groups

We genotyped nine groups, consisting of 207 accessions, by using 19 SSR markers. Heterozygosity of the nine groups was $H_{\mathrm{O}}=0.42-0.74$ and $H_{\mathrm{E}}=0.39-0.80$ (Table 2). Crossbred cultivar groups released after 1950 (CLH and MDC) had lower values than the other 7 groups. AR of the nine groups ranged from 3.2 to 9.6. AR of the Chinese pear groups (BRE and USS) showed the highest values (8.0 and 9.6) among the nine groups. On the other hand, AR of the crossbred cultivar groups $(\mathrm{CFH}$, $\mathrm{CLH}$, and MDC) decreased as the year of release became more recent $(4.6,3.5$, and 3.2 , respectively). The AR values of MDC were about half those of the local cultivar groups (KAN, NSJ, WJ).

\section{Bayesian statistical inference of the population structure}

To estimate the optimal number of genetic clusters $(K)$ in Structure, we calculated $\Delta K$ values (Table 3 ). The $\Delta K$ values were highest at $K=2$ in both the independent and correlated models. In both models, the two clusters corresponded to (1) wild individuals and Chinese pear groups (IWA, BRE, and USS) and (2) local and crossbred cultivar groups (KAN, NSJ, WJ, CFH, CLH and MDC), similar to the classification obtained by Iketani et al. [24]. In the independent model, the second-highest $\Delta K$ value occurred at $K=4$ (Table 3 ). Moreover, the value of $\ln \mathrm{P}(\mathrm{X} \mid \mathrm{K})$ seemed to plateau at $K=4$ (Fig. 1). Consequently we adopted $K=4$ as the optimal classification in the independent model. With $K=4$, the 207 accessions could be classified into four groups corresponding to (1) wild individuals from Iwate Prefecture (green cluster), (2) Chinese pear cultivars (yellow cluster), (3) local cultivars from the Kanto region and crossbred cultivars (red cluster), and (4) local cultivars from outside the Kanto region (blue cluster; Fig. 2a). We were not able to separate the local cultivars from the Kanto region from the crossbred cultivars by increasing the value of $K$ in the independent model. The new clusters that appeared at $K=6$

Table 2 Genetic characteristics of group analyzed using 19 SSRs

\begin{tabular}{lllll}
\hline Group number & Code & $H_{O}$ & $H_{E}$ & AR \\
\hline 1 & IWA & 0.69 & 0.71 & 6.4 \\
2 & BRE & 0.72 & 0.75 & 8.0 \\
3 & USS & 0.74 & 0.80 & 9.6 \\
4 & KAN & 0.72 & 0.66 & 5.1 \\
5 & NSJ & 0.68 & 0.71 & 6.1 \\
6 & WJ & 0.66 & 0.71 & 6.3 \\
7 & CFH & 0.69 & 0.61 & 4.6 \\
8 & CLH & 0.54 & 0.47 & 3.5 \\
9 & MDC & 0.42 & 0.39 & 3.2 \\
\hline
\end{tabular}

$H_{\mathrm{O}}$ observed heterozygosity, $H_{\mathrm{E}}$ expected heterozygosity, AR allelic richness
Table 3 Values of $\Delta K$ for $K=1$ to 10 in independent and correlated models

\begin{tabular}{lll}
\hline$K$ & \multicolumn{1}{l}{ Independent } & \\
\cline { 2 - 3 } & - & Correlated \\
2 & 1646.7 & - \\
3 & 14.3 & 1610.6 \\
4 & 102.3 & 6.9 \\
5 & 53.5 & 2.4 \\
6 & 2.4 & 4.1 \\
7 & 4.1 & 1.5 \\
8 & 1.6 & 2.0 \\
9 & 2.6 & 1.9 \\
10 & - & 2.1 \\
\hline
\end{tabular}

to 10 were distributed mainly in the Chinese pear cultivars.

On the other hand, no prominent $\Delta K$ was observed in the correlated model other than for $K=2$ (Table 3), and the value of $\ln \mathrm{P}(\mathrm{X} \mid K)$ seemed to plateau somewhere between $K=6$ and $K=10$, although it did not plateau as clearly as for the independent model (Fig. 1). However, we confirmed that the bar plot diagrams at $K=6$ (Fig. 2b) were similar across ten repetitions, suggesting that the clustering at $K=6$ in the correlated model has high reliability. The difference in genetic structure between $K=4$ in the independent model and $K=6$ in the correlated model was the appearance of a new cluster in the Chinese pear groups (cyan) and in the local cultivar group from the Kanto region (magenta; Fig. 2). At $K=6$, some accessions showed admixtures of different clusters (suggesting contributions from different populations), which was observed much less frequency in the $K=4$ classification. In particular, some crossbred cultivars had characteristics of both the red and magenta clusters when $K=6$, which we attribute to cross-hybridization between genotypes from different clusters in the pear

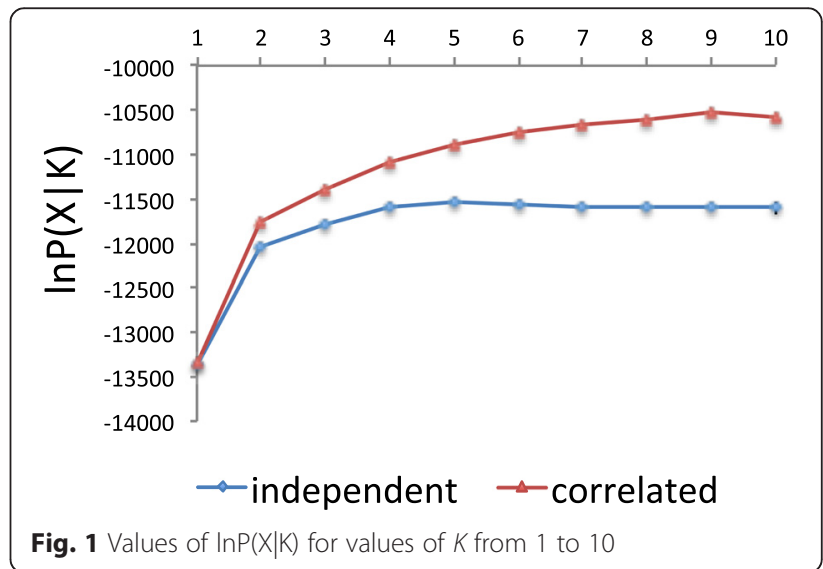


(a)
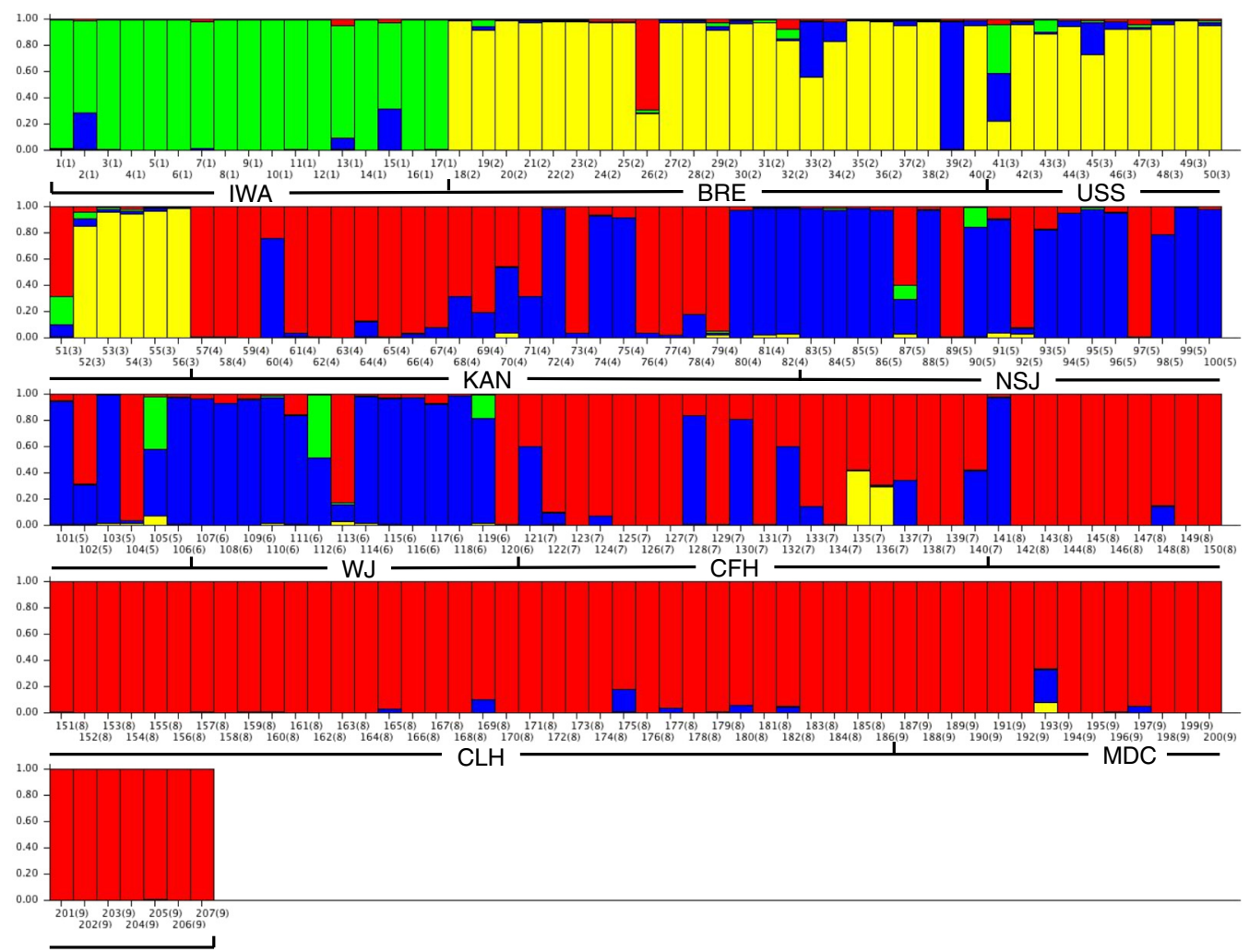

(b)

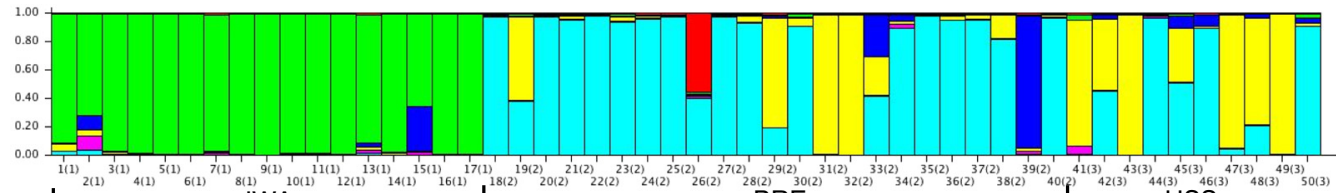

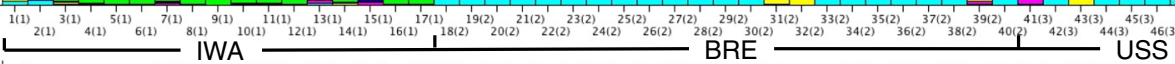
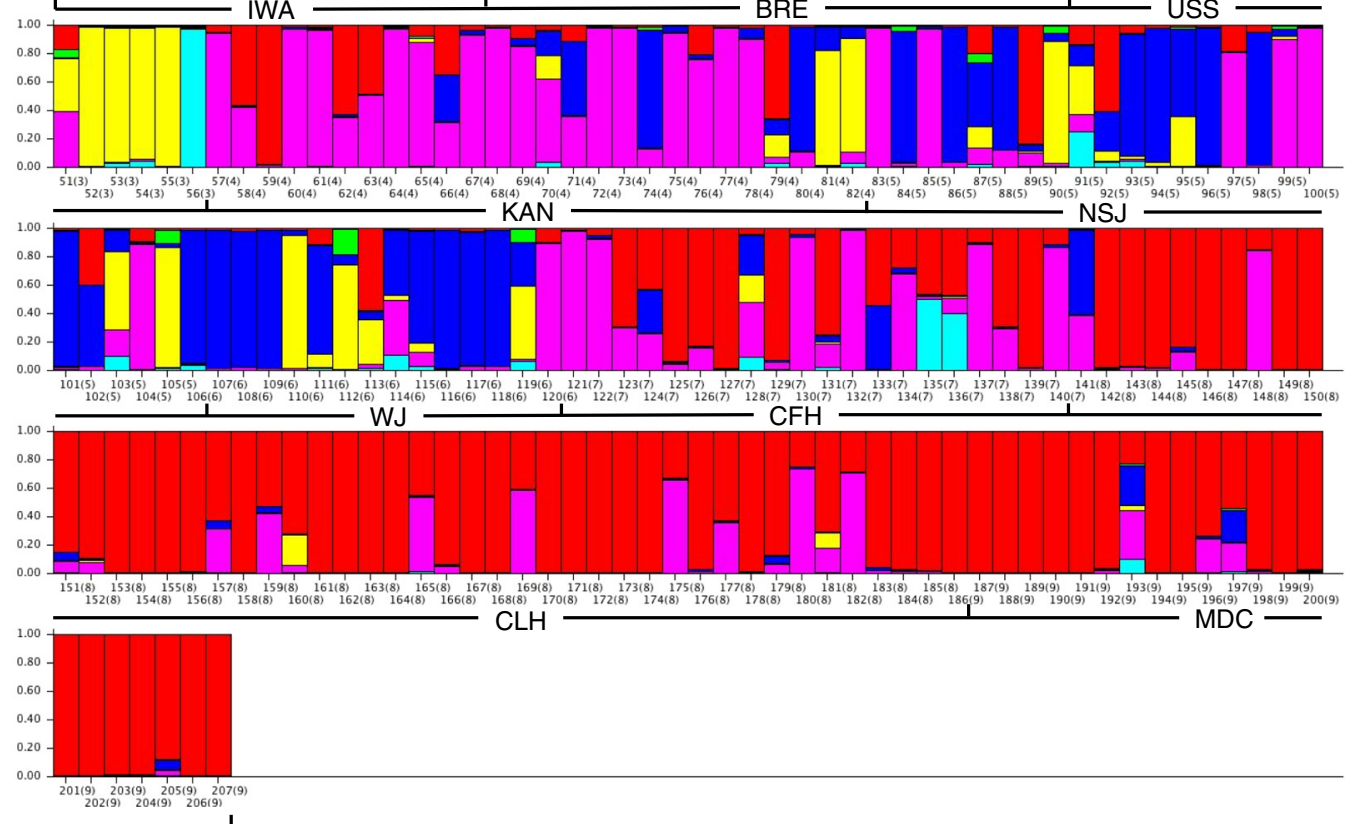

Fig. 2 A detailed bar plot diagram for (a) $K=4$ in the independent model and (b) $K=6$ in the correlated model. The first number under each bar represents the individual accession ID number (1-207); the second number (in parentheses) represents the group number (1-9). ID numbers and groups are defined in Table 1 
breeding program. Among the local cultivars from the Kanto region (KAN), only 'Nijisseiki' (ID =59) was dominated by the red cluster at $K=6$, probably because cultivars released in the 20th century and later are based on 'Nijisseiki' and its relatives.

\section{PCoA of the 207 accessions}

The first two informative PCo components (Fig. 3) explained $23.15 \%$ of the total variation. The results of PCoA were similar to those of the Structure analysis. The wild individual group (IWA) and Chinese pear groups (BRE, USS) appeared to be distinct from the other groups. BRE and USS showed similar distribution, as did NSJ and WJ. Crossbred cultivars (CFH, CLH, MDC) were plotted closer to 'Nijisseiki' (ID = 59) as the year of release became more recent. In particular, all of the MDC cultivars except 'Oushuu' (ID = 193) were distributed near 'Nijisseiki'. Some cultivars showed unexpected distributions; for example, Chinese pear cultivars 'Ya Gua Li' (ID = 26) and 'Manshuu Yaseinashi' (ID = 51) were plotted between the Japanese local cultivars and the Chinese pear cultivars. 'Saitama 2-1' $($ ID = 81) and 'Saitama 8' (ID = 82), both of which belong to the group of local cultivars from the Kanto region, were close to the Chinese pear groups.

We also calculated simple allele-sharing distances to estimate the genetic relationship between each pair of accessions (Additional file 3: Table S3). The average simple allele-sharing distances were $0.22,0.30,0.54$ and 0.73 between MDC and wild P. ussuriensis (IWA), Chinese pear cultivars (BRE and USS), local cultivars (KAN, NSJ, and $\mathrm{WJ})$, and crossbred cultivars (CFH, CLH, and MDC), respectively.

\section{Discussion}

Genetic relationships between modern Japanese pear cultivars and diverse genetic resources

We evaluated diverse genetic resources of Asian pear using Structure analysis, PCoA, and simple allelesharing distance. The results of Structure analysis and PCoA were consistent in that wild individuals and Chinese pear cultivars were classified as genetically

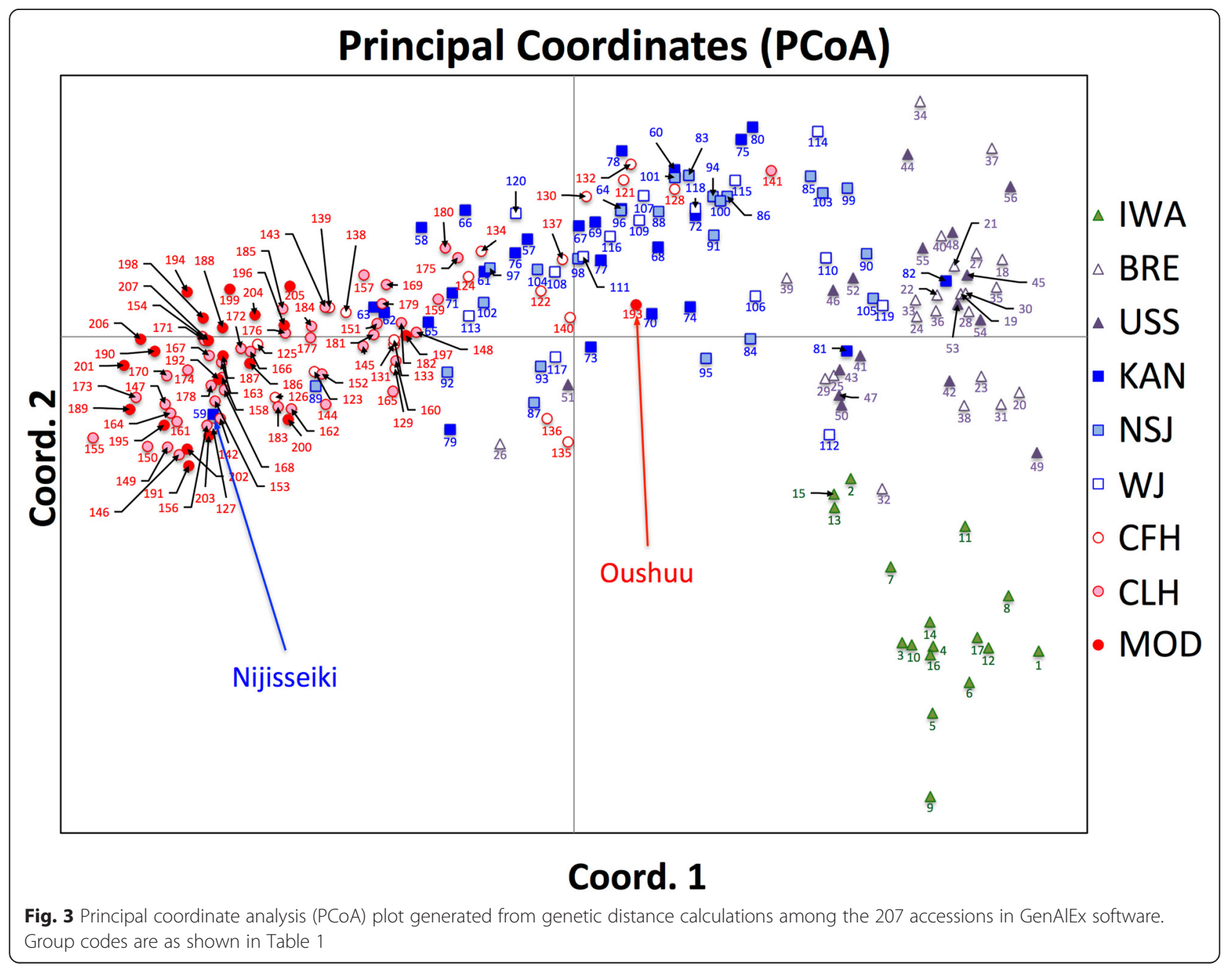


distinct from Japanese pear cultivars. This result is also in good agreement with previous studies [24, 25]. The modern cultivars seemed to be genetically close to local cultivars that originated in the Kanto region, especially 'Nijisseiki' (Figs. 2 and 3). Because modern cultivars were selected from 'Nijisseiki' and its relatives, this result was not unexpected. Both low heterozygosity and low AR were observed in Japanese pear modern cultivars, suggesting that the genetic diversity of modern cultivars has decreased over time. In the Structure result with $K=4$, almost all crossbred cultivars and modern cultivars showed "red" genetic background (i.e., were part of the cluster indicated by red shading in Fig. 2), which was characteristic of local cultivars from the Kanto region. When $K=6$, the "red" genetic background was shared by only 'Nijisseiki' and modern cultivars. In addition, almost all of the modern cultivars were plotted around 'Nijisseiki' in PCoA, and the average allele-sharing distance between modern cultivars and 'Nijisseiki' was high (0.76; Additional file 3: Table S3). These results suggest a marked biased in the genotypes of modern cultivars. Crossing among modern cultivars containing only the "red" genetic background would not generate a genotype that greatly exceeds the current performance of modern cultivars. To broaden genetic diversity and obtain superior genotypes in modern cultivars, we need to introduce genes from wild individuals and Chinese pear cultivars that are genetically different from modern Japanese pear cultivars.

\section{Breeding history of 'Oushuu', a cultivar with a diverse genetic background}

Among the modern cultivars, only 'Oushuu' (ID = 193) seemed to be distinct from the others in both Structure analysis and PCoA. This cultivar, released in 2003, is an offspring of a cross between C2 (an offspring of a cross between 'Lai Yang Ci Li' (ID = 50) and 'Nijisseiki') and 'Shinsetsu' (ID =141, an offspring of a cross between 'Imamuraaki' (ID = 108) and 'Okusankichi' (ID = 85)). 'Oushuu' showed both strong tree vigor and desirable fruit texture characteristics (e.g., soft flesh firmness) preferred in the Japanese market [35]. In the Structure result with $K=6$, 'Oushuu' had not only "red" genetic background (presumably from 'Nijisseiki') but also "cyan" (presumably from 'Lai Yang Ci Li'), "blue" (presumably from 'Imamuraaki'), and "magenta" (presumably from 'Okusankichi') genetic backgrounds. Its strong tree vigor may be caused by heterosis. The successful breeding history of 'Oushuu' indicates that it is possible to release new cultivars that have good fruit quality without repeatedly using 'Nijisseiki' and its relatives as parents.

\section{Cultivars showing unexpected genetic structure}

Some cultivars showed unexpected genetic structure and genetic relationships. 'Ya Gua Li' (ID = 26) and 'Manshuu
Yaseinashi' (ID $=51$ ) were classified into the Chinese pear group [25], but were plotted between Japanese local cultivars and Chinese pear cultivars in PCoA. 'Ya Gua Li' appears to have the genetic structure of both Chinese pear and local cultivars from the Kanto region. In fact, 'Ya Gua Li' and 'Nijisseiki' shared at least one allele at each of the 19 SSR markers, suggesting that 'Ya Gua Li' is a hybrid between Chinese pear and 'Nijisseiki'. This hybrid could have been mislabeled during genetic resource preservation. 'Manshuu Yaseinashi' had admixed genetic structure, but the results with $K=4$ and $K=6$ were different, i.e., it contained "blue" genetic background (found in Japanese local cultivars) when $K=4$ and "yellow" genetic background (found in Chinese pear cultivars) when $K=6$. Because the word "Manshuu" is the old name of a place in northeastern China and "Yaseinashi" means "wild pear" in Japanese, wild individuals from northeastern China will be key to clarifying the true genetic structure of 'Manshuu Yaseinashi'. Although 'Tang Li' (ID =39) was classified as BRE, it has an almost totally "blue" genetic background (characteristic of Japanese local cultivars) at both $K=4$ and $K=6$. Pear genetic resources are generally grafted onto seedling rootstocks of Japanese materials such as strain 'Mamenashi', the collective name of wild pear with small fruit. Thus, it is possible that 'Tang Li' had been mislabeled or mishandled during genetic resource preservation and is actually a Japanese rootstock genotype. We need to take care because these cultivars showing unexpected genetic structure are not appropriate for broadening the genetic diversity of Japanese pear cultivars. 'Saitama 2-1' (ID = 81) and 'Saitama 8' (ID = 82) are considered to be local cultivars from the Kanto region, because "Saitama" is the name of a prefecture in the Kanto region, but these cultivars were genetically close to the Chinese cultivar group in PCoA. As with 'Manshuu Yaseinashi', the Structure results for 'Saitama 2-1' and 'Saitama 8' were inconsistent between $K=4$ and $K=6$. Further analyses including verified Chinese materials are needed to identify the origin of these cultivars.

\section{Putative spreading patterns of local cultivars}

Local cultivars that originated outside the Kanto region seem to have been important contributors to the genetic diversity of cultivated pears. It has been reported that cultivars that originated near the Sea of Japan or Kyushu island tend to show late ripening and long fruit, whereas cultivars that originated in the Kanto region show early ripening and oblate fruit [36, 37]. However, some local cultivars that originated outside the Kanto region ('Awayuki' (ID = 89), 'Kounowatashi' (ID = 92), 'Kunitomi' (ID = 97), 'Touhou' (ID = 102), and 'Waseaka' (ID = 104)) showed genetic background similar to those that originated in the Kanto region at $K=4$, suggesting that these 
cultivars might have been introduced from the Kanto region into other regions. In fact, it was reported that 'Waseaka' was introduced into Niigata Prefecture from the Kanto region, and 'Kunitomi' was discovered from offspring of 'Taihaku' (ID = 76), which originated in the Kanto region [26]. Similarly, these other cultivars might have been introduced from the Kanto region into other regions. In fruit tree species, it is common that local cultivars with traits of interest are vegetatively propagated and carried to other regions [38-41]. We need to take into account the spread of cultivars when classifying local cultivars by geographical origin.

\section{Possible origin of local cultivars in Japan}

Iketani et al. [24] showed that local cultivars in Japan are genetically closer to Chinese cultivars than to wild individuals of $P$. ussuriensis collected from high plateaus in Iwate Prefecture. In the Structure result at $K=6$, some local cultivars in Japan showed "yellow" genetic background, characteristic of Chinese pear cultivars. The history of pear breeding before the early modern period in Japan is still unclear, but some local cultivars may have been domesticated from Chinese materials. Jiang et al. [42] suggested that there were opportunities for ancient cultivar exchange between Japan and eastern China. Thus, the "yellow" genetic background might have been introduced by genetic exchange with Chinese cultivars.

\section{Future breeding strategy for the Japanese pear breeding program}

Our data strongly support the assumption that introgression of germplasm from Chinese pear cultivars and wild individuals into modern cultivars is an effective way to broaden genetic diversity. Thus, it might be easier to develop new cultivars using Chinese pear cultivars, which are already domesticated and bear large fruit. In fact, 'Oushuu' was selected from the first backcross of a Chinese cultivar to several Japanese cultivars and has good fruit quality. On the other hand, introgression of germplasm from indigenous species into modern cultivars seems to be challenging; for example, their fruit size is smaller than that of recent cultivars [43]. However, there are many hybrids between P. pyrifolia and P. ussuriensis, some of which bear fruits larger than those of wild individuals of the latter species [44]. In particular, local cultivar 'Natsunashi' would be good material for a pear breeding program because it shows early ripening and has high concentrations of ethyl and methyl esters, which are desirable flavor components.

Trends in genetic diversity during organized breeding of annual and perennial crops

Owing to the progress of organized breeding (scientific breeding), the genetic diversities of several annual crops, including maize [45, 46], rice [47], sorghum [48], tobacco [49], and wheat [50], decreased at one point during the latter part of the 20th century. According to a meta-analysis of genetic diversity trends in annual crops during the 20th century, diversity was reduced significantly in the 1960s compared with the 1950s, than then recovered from the 1970s to the 1990s [51]. Breeders probably averted the narrowing of the germplasm base and subsequently increased the genetic diversity in these crops through the introgression of novel materials. However, very few genetic studies have focused on genetic diversity trends during the organized breeding of perennial crops, although inbreeding depression has been a concern of fruit breeders $[6,51]$. Our results clarify that loss of genetic diversity has occurred in a fruit crop, as has been reported in annual crops. However, the genetic diversity in perennial crops seems to have declined more slowly than that in annual crops, possibly because perennial crops have a longer juvenile phase and fewer sexual cycles than annual crops. Japanese pear breeding may have just reached the stage reached by annual crop breeding in the 1960s or 1970s. Given the availability of genetic resources and molecular tools, we now have the capability to work toward increasing the genetic diversity of pear cultivars.

\section{Conclusions}

In this study, we clarified the genetic relationship between Japanese pear modern cultivars and diverse genetic resources including wild individuals, Chinese pear cultivars, and local cultivars. The genetic diversity of modern cultivars decreased as the year of release became more recent. The modern cultivars were genetically close to local cultivar 'Nijisseiki', which had been repeatedly used as a parent in our breeding program, confirming that Japanese pear breeding has been carried out within a narrow gene pool. On the basis of these findings, we plan to broaden the genetic diversity in the NIFTS pear breeding program by introgressing germplasm from Chinese pear and wild individuals that are genetically distinct from modern cultivars. We also determined that Structure analysis and PCoA are effective for evaluating the degree of inbreeding and genetic relationships among accessions. The information obtained in this study will be useful for pear breeders as well as other fruit breeders who have problems with inbreeding depression in their breeding programs.

\section{Additional files}

Additional file 1: Table S1. Names, accession numbers, and breeding information for the 207 accessions used in this study. (PDF 154 kb)

Additional file 2: Table S2. Description of the 19 simple sequence repeat (SSR) markers used in this study. (XLSX $12 \mathrm{~kb}$ )

Additional file 3: Table S3. Simple allele-sharing distances for the 207 accessions used in this study. (XLSX 259 kb) 


\section{Abbreviations}

$A R$, allelic richness; BRE, Chinese pear cultivars generally considered to be P. bretschneideri; CFH, Japanese pear crossbred cultivars and breeding lines from the first half of the 20th century; $\mathrm{CLH}$, Japanese pear crossbred cultivars and breeding lines from the latter half of the 20th century; $H_{E}$, expected heterozygosity; $H_{\mathrm{O}}$, observed heterozygosity; IWA, wild individuals of P. ussuriensis collected from the Hayasaka-Kogen high plateau in Iwate Prefecture; KAN, Japanese pear local cultivars that originated in the Kanto region of Japan; MDC, Modern cultivar released in the 21st century or breeding line developed during that time; NIFTS, Institute of Fruit Tree and Tea Science, NARO; NSJ, Japanese pear local cultivars that originated near the Sea of Japan; PCoA, principal coordinate analysis; SSR, simple sequence repeat; USS, Chinese pear cultivars generally considered to be $P$. ussuriensis; WJ, Japanese pear local cultivars that originated in western Japan

\section{Acknowledgments}

We are deeply indebted to all the people involved in the Japanese pear breeding program at the Institute of Fruit Tree and Tea Science, NARO, Japan.

\section{Funding}

No funding was obtained for this study.

\section{Availability of supporting data}

The datasets supporting the conclusions of this article are included within the article and its additional files.

\section{Competing interests}

The authors declare that they have no competing interests.

\begin{abstract}
Authors' contributions
SN participated in the design of the experiments, genotyped SSRs, interpreted the data, and wrote the paper. HI participated in the design of the experiments, genotyped SSRs, and revised the manuscript. TY provide SSR markers and genotyped SSRs. NT and TS participated in the design of the experiments and provided the plant materials. All the authors read and approved the manuscript.
\end{abstract}

\section{Ethics approval and consent to participate}

Not applicable.

\section{Consent for publication}

Not applicable.

\section{Author details}

${ }^{1}$ Institute of Fruit Tree and Tea Science, NARO (NIFTS), 2-1 Fujimoto, Tsukuba, Ibaraki 305-8605, Japan. ²Department of Biosphere-Geosphere Science, Faculty of Biosphere-Geosphere Science, Okayama University of Science, 1-1 Ridai-cho, Kita-ku, Okayama 700-0005, Japan.

\section{Received: 22 January 2016 Accepted: 24 May 2016}

Published online: 14 June 2016

\section{References}

1. Melville AH, Galletta GJ, Draper AD, Ng TJ. Seed germination and early seedling vigor in progenies of inbred strawberry selections. HortSci. 1980;15:749-50.

2. Lyrene P. Inbreeding depression in rabbiteye blueberries. HortSci. 1983;18:226-7

3. Cram W. Some effects of self-, cross-, and open-pollinations in Picea pungens. Can J Bot. 1984;62:392-5.

4. Yamada M, Yamane H, Ukai Y. Genetic analysis of Japanese persimmon fruit weight. J Am Soc Hortic Sci. 1994;119:1298-302.

5. Durel C, Bertin P, Kremer A. Relationship between inbreeding depression and inbreeding coefficient in maritime pine (Pinus pinaster). Theor Appl Genet. 1996;92:347-56

6. Noiton DA, Alspach PA. Founding clones, inbreeding, coancestry, and status number of modern apple cultivars. J Am Soc Hortic Sci. 1996;121:773-82.

7. Segura JA. Negative inbreeding effects in tree fruit breeding: selfcompatibility transmission in almond. Theor Appl Genet. 2007;115:151-8.

8. Sato A Sawamura Y Takada N, Hirabayashi T. Relationship between inbreeding coefficients and plant height of 1-year-old seedlings in crosses among Japanese pear (Pyrus pyrifolia Nakai) cultivars/selections. Sci Hortic 2008;117:85-8

9. Onoue N, Yamada M, Yamamoto T, Terakami S, Nishitani C, Kunihisa M, et al. Kinship and inbreeding estimates based on microsatellite markers in breeding of Japanese pear (Pyrus pyrifolia Nakai). Euphytica. 2015;205:539-55.

10. Zamir D. Improving plant breeding with exotic genetic libraries. Nat Rev Genet. 2001;2:983-9.

11. Miller AJ, Gross BL. From forest to field: perennial fruit crop domestication. Am J Bot. 2011:98:1389-414.

12. Nishio S, Takada N, Yamamoto T, Terakami S, Hayashi T, Sawamura Y, Saito T. Mapping and pedigree analysis of the gene that controls the easy peel pellicle trait in Japanese chestnut (Castanea crenata Sieb. et Zucc.). Tree Genet Genomes. 2013:9:723-30.

13. Gu C, Sponberg SA. Pyrus. In: Wu Z, Raven PH, Honf DY, editors. Flora of China. Vol. 9. Beijing: Science Press; 2003. p. 173-19.

14. Yü TT, Ku TC. Pyrus. In: Yü TT, editor. Flora Reipublicae Popularis Sincae. Vol. 36. Beijing: Science Press; 1974. p. 354-72.

15. Kikuchi A. Horticulture of fruit trees, vol. 1. Tokyo: Yokendo; 1948.

16. Rehder A. Synopsis of the Chinese species of Pyrus. Proc Amer Acad Arts Sci. 1915;50:225-41.

17. Yü TT. Classification of the fruit trees in China. Beijing: Agriculture Press; 1979.

18. Kimura T, Shi YZ, Shoda M, Kotobuki K, Matsuta N, Hayashi T, et al. Identification of Asian pear varieties by SSR analysis. Breed Sci. 2002:52:115-21.

19. Teng YW, Tanabe K, Tamura F, Itai A. Genetic relationships of Pyrus species and cultivars local to East Asia revealed by randomly amplified polymorphic DNA markers. J Am Soc Hortic Sci. 2002;127:262-70.

20. Bao L, Chen KS, Zhang D, Cao YF, Yamamoto T, Teng YW. Genetic diversity and similarity of pear (Pyrus L.) cultivars local to East Asia revealed by SSR (simple sequence repeat) markers. Genet Resour Crop Evol. 2007;54:959-71.

21. Bao L, Chen KS, Zhang D, Li XG, Teng YW. An assessment of genetic variability and relationships within Asian pears based on AFLP (amplified fragment length polymorphism) markers. Sci Hortic. 2008;116:374-80.

22. Campbell CS, Greene CW, Dickinson TA. Reproductive biology in subfam. Maloideae (Rosaceae). Syst Bot. 1991:6:333-49.

23. Katayama $\mathrm{H}$, Adachi S, Yamamoto $\mathrm{T}$, Uematsu $\mathrm{C}$. A wide range of genetic diversity in pear (Pyrus ussuriensis var. aromatica) genetic resources from Iwate, Japan revealed by SSR and chloroplast DNA markers. Genet Resour Crop Evol. 2007:54:1573-85.

24. Iketani $H$, Yamamoto $T$, Katayama H, Uematsu C, Mase N, Sato Y. Introgression between local and prehistorically naturalized (archaeophytic) wild pear (Pyrus spp.) populations in Northern Tohoku, Northeast Japan. Conserv Genet. 2010;11:115-26.

25. Iketani H, Katayama H, Uematsu C, Mase N, Sato Y, Yamamoto T. Genetic structure of East Asian cultivated pears (Pyrus spp.) and their reclassification in accordance with the nomenclature of cultivated plants. Plant Syst Evol. 2012;298:1689-700.

26. Kajiura I, Sato Y. Recent progress in Japanese pear (Pyrus pyrifolia Nakai) breeding and description of cultivars based on literature review. Bull Fruit Tree Res Stn Extra. 1990:1:1-329.

27. Machida Y, Kozaki I. Quantitative studies on the fruit quality in Japanese pear (Pyrus serotina Rehder) breeding. 2: Statistical analyses of a hybrid seedling population. J Jpn Soc Hortic Sci. 1976;44:324-29.

28. Tamura F. Japanese pear. In: Jpn Soc Hort Sci, editor. Horticulture in Japan 2006. Kyoto: Shoukadoh Publication; 2006. p. 50-8.

29. Saito T, Sato Y, Sawamura Y, Shoda M, Takasaki-Yasuda T, Kotobuki K. Dual recognition of $S_{1}$ and $S_{4}$ pistils by $S_{4}^{s m}$ pollen in self-incompatibility of Japanese pear (Pyrus pyrifolia Nakai). Tree Genet Genomes. 2012;8:689-94.

30. Peakall R, Smouse PE. GENALEX 6: genetic analysis in Excel. Population genetic software for teaching and research. Mol Ecol Notes. 2006;6:288-95.

31. Goudet J. FSTAT, a program to estimate and test gene diversities and fixation indices (version 2.9. 3). 2001.

32. Pritchard JK, Stephens M, Donnelly P. Inference of population structure using multilocus genotype data. Genetics. 2000;155:945-59.

33. Evanno G, Regnaut S, Goudet J. Detecting the number of clusters of individuals using the software STRUCTURE: a simulation study. Mol Ecol. 2005:14:2611-20.

34. Bowcock AM, Ruizlinares A, Tomfohrde J, Minch E, Kidd JR, Cavallisforza LL. High-resolution of human evolutionary trees with polymorphic microsatellites. Nature. 1994;368:455-7.

35. Kotobuki K, Saito T, Machida Y, Kajiura I, Sato Y, Masuda R, et al. New Japanese pear cultivar 'Oushuu'. Bull Natl Inst Fruit Tree Sci. 2004;4:41-51. 
36. Kajiura I, Suzuki S. Variations in fruit shape of Japanese cultivated pear varieties; geographic differentiation and changes caused by breeding. Japan J Breed. 1980;30:309-28.

37. Kajiura I, Omura M. Determinations of the optimum maturity for harvest and the best harvest index, and the historical changes of the maturation of Japanese pear cultivars (Pyrus serotina Rehd. var. culta). Bull Fruit Tree Res Stn A. 1982;9:61-113.

38. Pereira-Lorenzo S, Ramos-Cabrer AM, Díaz-Hernández MB. Evaluation of genetic identity and variation of local apple cultivars (Malus $\times$ domestica Borkh.) from Spain using microsatellite markers. Genet Resour Crop Evol. 2007:54:405-20.

39. Crespan M, Calo A, Giannetto S, Sparacio A, Storchi P, Costacurta A. 'Sangiovese' and 'Garganega' are two key varieties of the Italian grapevine assortment evolution. Vitis. 2008;47:97-104.

40. Nishio S, Yamamoto T, Terakami S, Sawamura Y, Takada N, Saito T. Genetic diversity of Japanese chestnut cultivars assessed by SSR markers. Breed Sci. 2011:61:109-20.

41. Nishio S, Iketani H, Fujii H, Yamamoto T, Terakami S, Takada N, et al. Use of population structure and parentage analyses to elucidate the spread of local cultivars of Japanese chestnut. Tree Genet Genomes. 2014;10:1171-80.

42. Jiang Z, Tang F, Huang H, Hu H, Chen Q. Assessment of genetic diversity of Chinese sand pear landraces (Pyrus pyrifolia Nakai) using simple sequence repeat markers. HortSci. 2009;44:619-26.

43. Katayama H, Uematsu C. Pear (Pyrus species) genetic resources in Iwate, Japan. Genet Resour Crop Evol. 2006:53:483-98.

44. Katayama $\mathrm{H}$, Ohe M, Sugawara E. Diversity of odor-active compounds from local cultivars and wild accessions of Iwateyamanashi (Pyrus ussuriensis var. aromatica) revealed by Aroma Extract Dilution Analysis (AEDA). Breed Sci. 2013:63:86-95

45. Lu H, Bernardo R. Molecular marker diversity among current and historical maize inbreds. Theor Appl Genet. 2001;103:613-7.

46. Reif JC, Hamrit S, Heckenberger M, Schipprack W, Maurer HP, Bohn M, et al. Trends in genetic diversity among European maize cultivars and their parental components during the past 50 years. Theor Appl Genet. 2005:111:838-45.

47. Qi Y, Zhang D, Zhang H, Wang M, Sun J, Wei X, et al. Genetic diversity of rice cultivars (Oryza sativa L.) in China and the temporal trends in recent fifty years. Chin Sci Bull. 2006;51:681-8.

48. Jordan D, Tao Y, Godwin I, Henzell R, Cooper M, Mclntyre C. Loss of genetic diversity associated with selection for resistance to sorghum midge in Australian sorghum. Euphytica. 1998;102:1-7.

49. Moon H, Nicholson J, Heineman A, Lion K, van der Hoeven R, Hayes A, et al. Changes in genetic diversity of US flue-cured tobacco germplasm over seven decades of cultivar development. Crop Sci. 2009:49:498-508.

50. Reif JC, Zhang P, Dreisigacker S, Warburton ML, van Ginkel M, Hoisington D, Bohn M. Wheat genetic diversity trends during domestication and breeding. Theor Appl Genet. 2005;110:859-64

51. Van de Wouw M, van Hintum T, Kik C, van Treuren R, Visser B. Genetic diversity trends in twentieth century crop cultivars: a meta analysis. Theor Appl Genet. 2010;120:1241-52.

\section{Submit your next manuscript to BioMed Central and we will help you at every step:}

- We accept pre-submission inquiries

- Our selector tool helps you to find the most relevant journal

- We provide round the clock customer support

- Convenient online submission

- Thorough peer review

- Inclusion in PubMed and all major indexing services

- Maximum visibility for your research

Submit your manuscript at www.biomedcentral.com/submit

) Biomed Central 